\title{
Synthesis of Zinc Nanoparticles and Its Application in Treatment of Municipal Water of Anantapur
}

\author{
S. Sharada ${ }^{1 *}$, Srikanth Pusarla ${ }^{1}$ \\ Department of Chemical Engineering, JNTUACE, Anantapur (A.P) \\ *Author for correspondence: e-mail:sharada01s@gmail.com, Ph: +91-9642853207,Fax: 918554-273007
}

\begin{abstract}
Water is polluted by the industries like construction and mining, food processing from domestic and agricultural wastes and by micro logical agents. There are different methods are worn for purification of water, but these water treatment techniques require large area, high capital investment, operation and maintenance cost. The contamination of water is a major problem in the global consequence. The metal oxide semiconductor like $\mathrm{ZnO}$ is capable of in service effectively and efficiently for the water treatment. ZnO nanoparticles are synthesized from direct precipitation method. Zinc nitrate showed best performance, yielding ZnO particles with the smallest average grain size. At optimal conditions, ZnO nanoparticles with average size of 16 nm were obtained. The synthesized ZnO nanoparticles were characterized by scanning electron microscope (SEM), X-ray diffraction (XRD), UV-Vis absorption spectroscopy. After synthesis of ZnO nanoparticles, The ZnO nanoparticles are coated on filter candles by using non-woven fiber. These filter candles are fitted into the equipment of water filteration. The treatment of nanoparticles to the drinking water has been examined by various water testing analysis. The work resulted economically feasible and Environmental freindly in all aspects.
\end{abstract}

Keywords: contamination, nanoparticles, direct precipitation, X-ray diffraction, non-woven fiber

\section{Introduction}

Muncipal water is used for drinking, cooking, cleaning, agriculture, etc. In which only $0.1 \%$ is used for the drinking purpose,remaining percentage of water is used for the domestic usage. Recent advances of nanotechnology used for purification water. The nanomaterials used for $\mathrm{ZnO}$ has the antibacterial properties. The zinc oxide occurs in a very affluent in variety of structures and offers a wide range of properties. The variety of methods for $\mathrm{ZnO}$ production, such as vapour deposition, precipitation in water solution, hydrothermal synthesis, the sol-gel process, precipitation from micro emulsions and mechano chemical processes, makes it possible to obtain products with particles differing in shape, size and spatial structure. $\mathrm{ZnO}$ is having the high surface area, Due to this property $\mathrm{ZnO}$ used as water treatment.

\section{Synthesis of $\mathrm{ZnO}$ nanoparticles}

$\mathrm{ZnO}$ nanoparticles were synthesized by direct precipitation method using zinc nitrate hexa hydrate and $\mathrm{KOH}$ as precursors brought for SL SCIENTIFICS. In this work, the aqueous solution $(0.2 \mathrm{M})$ of zinc nitrate $(\mathrm{Zn}(\mathrm{NO} 3) 2.6 \mathrm{H} 2 \mathrm{O})$ and the solution $(0.4 \mathrm{M})$ of $\mathrm{KOH}$ were prepared with deionized water, respectively. The $\mathrm{KOH}$ solution was slowly added into zinc nitrate solution at room temperature under vigorous stirring, which resulted in the formation of a white suspension. The white product was centrifuged at $5000 \mathrm{rpm}$ for $20 \mathrm{~min}$ and washed three times with distilled water, and washed with absolute alcohol at last. The obtained product was calcined at $500{ }^{\circ} \mathrm{C}$ in air atmosphere for $3 \mathrm{hr}$.

\subsection{Processing of zinc oxide nanoparticles coated fiber glass mat:}

The synthesized $\mathrm{ZnO}$ nanoparticles are mixed with the distilled water, the colloidal solution of $\mathrm{ZnO}$ nanoparticles with water is obtained. Then the prepared solution is poured into the spray bottle. By using the spray bottle, the nanoparticles are sprayed on the fiberglass mat. The nanoparticles are stick to the surface of the fiber glassmat. Then the fiber glassmate is encircled on the ceramic filter candle. After nano particle coated filter candles are fix them into water purifier.

\section{2.}

Water sample analysis of Municipal water:

After the synthesis of Zinc Oxide nanoparticles. The particles were coated onto candles with fiber glass then the filters were dried at Room temperature for a period of $12 \mathrm{Hrs}$.the obtained filters were used as nano filter candles that are used for the treatment of Municipal tap water . After the process treatment which was treated in double store tank. After the process the treated water was used for the analysis of the samples taken and to to check the presence of minerals and acids that's leads to the cause of ill health.

\subsection{Desiging the purifier:}

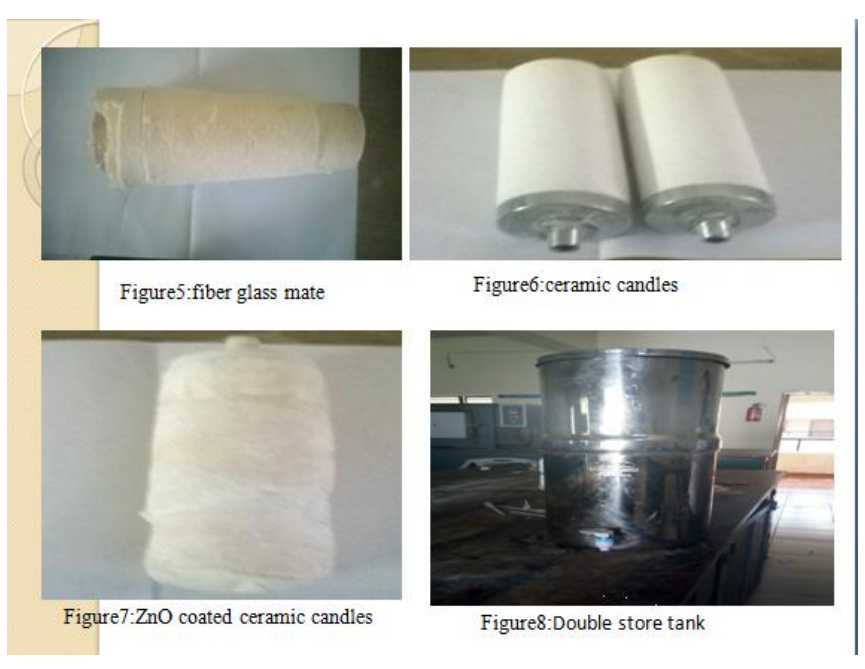




\section{Results and Discussions}

\subsection{Characterization of $\mathrm{ZnO}$}

\subsubsection{UV-Visible spectroscopy}

The UV-Vis spectrum showed absorption band at $324 \mathrm{~nm}$. The band-gap energy obtained was $3.32 \mathrm{eV}$.

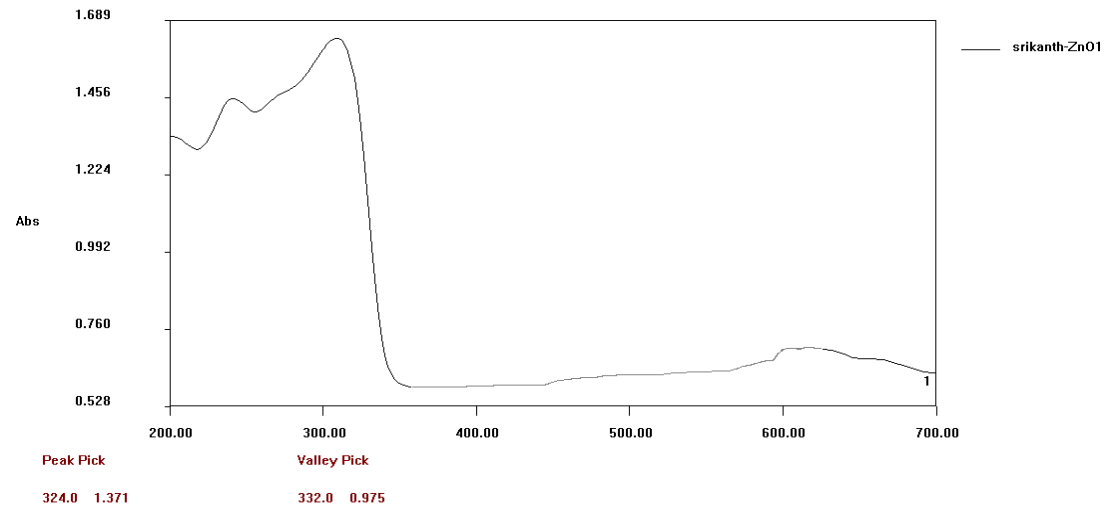

Figure 1: UV-visible spectroscopy of $\mathrm{ZnO}$ nanoparticles

\subsubsection{FTIR analysis}

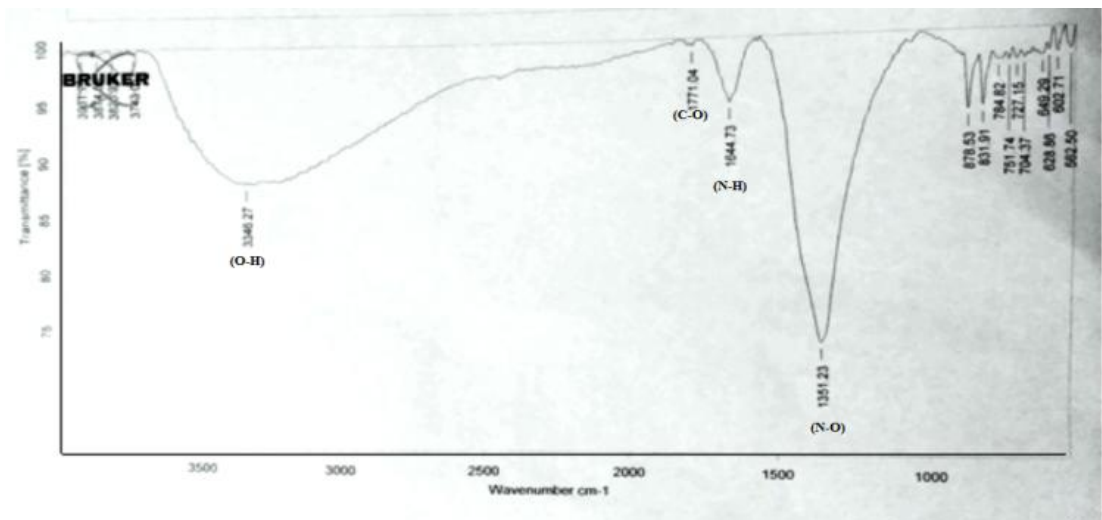

Figure 2: Fourier transform infrared spectroscopy result of $\mathrm{ZnO}$ nanoparticles

The O-H and C-O stretch bands are observed at $3346.27 \mathrm{~cm}^{-1}$ and $1771.04 \mathrm{~cm}^{-1}$. The N-H and N-O stretch bands are observed at $1644.73 \mathrm{~cm}^{-1}$ and $1351.23 \mathrm{~cm}^{-1}$

\subsubsection{XRD analysis}

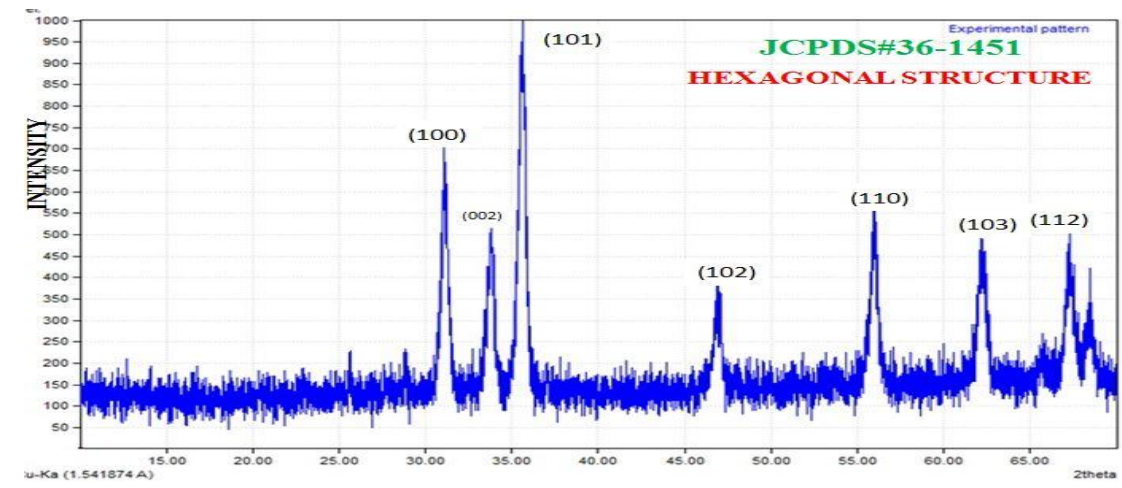

Figure 3: XRD pattern of $\mathrm{ZnO}$ nanoparticles

XRD patterns are matching with JCPDS 36-1451 resembling hexagonal wurtzite structure Crystalline size obtained was 20.9 $\mathrm{nm}$ using Scherer's equation. The peaks at $2 \theta=31.67^{\circ}, 34.31^{\circ}, 36.14^{\circ}, 47.40^{\circ}, 56.52^{\circ}, 62.73^{\circ}, 66.28^{\circ}, 67.91^{\circ}, 69.03^{\circ}$, and $^{\circ}$ $72.48^{\circ}$ were assigned to (100), (002), (101), (102), (110), (103), (200), (112), (201), and (004) of ZnO NPs. 
International Journal of Science and Research (IJSR)

ISSN (Online): 2319-7064

Index Copernicus Value (2015): 78.96 | Impact Factor (2015): 6.391

\subsubsection{Water experimental analysis}

\begin{tabular}{|c|c|c|c|}
\hline Volumetric analysis & Normal water & $\begin{array}{c}\text { Before ZnO coating water } \\
\text { sample }\end{array}$ & After ZnO coating water sample \\
\hline $\mathrm{pH}$ & 8 & 8.3 & 7.5 \\
\hline TDS & 531 & 507 & 188 \\
\hline mineral acidity(mg/l) & 50 & 40 & 28 \\
\hline Phenolphthalein acidity(mg/l) & 60 & 40 & 18 \\
\hline Phenolphthalein alkalinity(mg/l) & 86 & 80 & 70 \\
\hline total alkalinity(mg/l) & 480 & 400 & 290 \\
\hline
\end{tabular}

\section{Conclusions}

$\mathrm{ZnO}$ nanoparticles are prepared by direct precipitation method having $20.9 \mathrm{~nm}$. The UV-Vis spectroscopic study shows confirmed the reduction of metal ion and formation of nanoparticles with peak at $324 \mathrm{~nm}$. The XRD analysis shows that $\mathrm{ZnO}$ nanoparticles are having Hexagonal Wurzite structure.TDS values less than the $300 \mathrm{ppm}$ is desirable for drinking and the $\mathrm{pH}$ value is near to 7.The acidity is closed to $10 \mathrm{mg} / \mathrm{l}$ and the alkalinity is less than the $200 \mathrm{mg} / \mathrm{l}$, this water is desirable for drinking

\section{References}

[1] C. W. Bunn, "The lattice-dimensions of zinc oxide," Proc. Phys. Soc. London 47: 835, 1935.

[2] D. R. Lide (editor), CRC Handbook of Chemistry and Physics, CRC Press, New York, 73rd edition, 1992.

[3] D. C. Look, "Recent advances in $\mathrm{ZnO}$ materials and devices," Mat. Sci. Eng. B. 80:383, 2001.

[4] D. C. Look, D. C. Reynolds, J. R. Size love, R. L. Jones, C. W. Litton, G. Cantwell and W. C.Harsch, Electrical properties of bulk ZnO," Solid State Commun. 105: 399, 1998.

[5] Y. Segawa, A. Ohtomo, M. Kawasaki, H. Koinuma, Z. K. Tang, P. Yu and G. K. L. Wong, "Growth of $\mathrm{ZnO}$ thin films by laser-MBE: Lasing of exciton at room temperature," Phys. Stat. Sol. 202: 669, 1997.

[6] J. E. Nause, "ZnO broadens the spectrum," III-Vs Review 12: 28, 1999.

[7] J. E. Nause, "Fluorescent substrate offers route to phosphor-free LEDs," Comp. Semicond. 11: 29, 2005.

[8] S. O. Kucheyev, J. S. Williams, C. Jagadish, J. Zou, C. Evans, A. J. Nelson and A. V.Hamza, "Ionbeamproduced structural defects in $\mathrm{ZnO}$," Phys. Rev. B 67: 094 115, 2003.

[9] C. Coskun, D. C. Look, G. C. Farlow and J. R. Size love, "Radiation hardness of $\mathrm{ZnO}$ at low temperatures," Semicond. Sci. Technol. 19: 752, 2004.

[10] S. O. Kucheyev, J. S. Williams and C. Jagadish, "Ionbeam-defect processes in group III nitrides and $\mathrm{ZnO}$," Vacuum 73: 93, 2004.29

[11] Scott, J.R. and Barnett, T.C. (2006) Surface proteins of gram-positivebacteria and how they get there. Annu. Rev. Microbiol. 60, 397-423

[12] Witte, W. (2004) International dissemination of antibiotic resistant strains of bacterial pathogens. Infect. Genet. Evol. 4, 187-1913

[13] Oldenburg, A.L. et al. (2004) Magnetic contrast agents for opticalcoherence tomography. Proc. of SPIE 5316, 91-984
[14] Rakow, N.A. and Suslick, K.S. (2000) A colorimetric sensor array for odour visualization. Nature 406, 7107135

[15]Baker-Austin, C. et al. (2006) Co-selection of antibiotic and metalresistance. Trends Microbiol. 14, $176-182$ 